\title{
Stress-Strain Behavior - Deformation Degree Relationship Investigation of Alloy CrNi60WTi
}

Yaroslav Kosmatskiy*, Nikolai Fokin, Kseniya Yakovleva, Vladislav Nikolenko, Boris Barichko, Sergei Zakharov

The Russian Research Institute of the Tube \& Pipe Industries, Joint Stock Company (RUSNITI JSC); 30, Novorossijskaya Str., Chelyabinsk 454139, Russia

\section{Corresponding Author Email: Kosmatski@ rosniti.ru}

https://doi.org/10.18280/ti-ijes.650115

Received: 23 December 2020

Accepted: 2 March 2021

\section{Keywords:}

cold deformation, cold rolling, nickel-based alloys, CrNi60WTi, degree of deformation, plasticity, mechanical properties, deformation capacity, plastic deformation

\begin{abstract}
The article presents the results of a research of the dependence of the mechanical properties of the CrNi60WTi alloy on the degree of cold deformation. As part of the study, five samples were taken from a pipe with an outer diameter of $89.0 \mathrm{~mm}$ and a wall thickness of $11.0 \mathrm{~mm}$. The samples were cold-deformed to varying degrees and static tensile tests were performed on an SSI MTSInsight tensile testing machine. Based on the test results, the dependences of the mechanical properties on the degree of cold deformation were calculated.
\end{abstract}

\section{INTRODUCTION}

Nickel-based alloys are used in mechanical engineering, chemical industry, electrical engineering, electronics and power plants. High alloy nickel alloys are sometimes referred to as "superalloys" [1-5].

The issues of deformability of nickel-based alloys without fracture have been studied insufficiently. There is a need to study the deformability of nickel-based alloys, depending on the conditions of deformation [6-10].

This article discusses the issue of changing the mechanical properties of a nickel-based alloy of the CrNi60WT grade during its cold deformation. Experimental studies were carried out to determine the range of permissible degrees of cold plastic deformation of the CrNi60WT alloy.

\section{METHOD FLOW}

A hot-extruded pipe with a diameter of $89.0 \mathrm{~mm}$ and a wall thickness of $11.0 \mathrm{~mm}$ from an alloy of the CrNi60WT grade was used as a starting material. Five cylindrical bars with a diameter of $10 \mathrm{~mm}$ and a length of $210 \mathrm{~mm}$ were taken from the pipe (Figure 1).

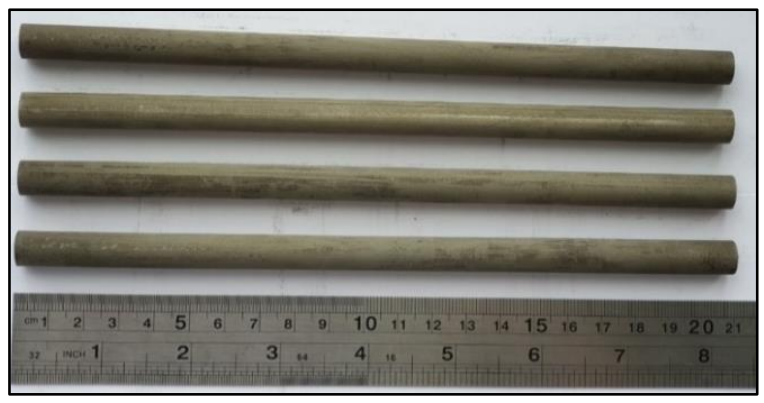

Figure 1. Bars made of alloy grade CrNi60WTi
A two-roll stand was used for cold deformation of the bars. The bars were deformed in $110 \mathrm{~mm}$ roll calibers according to the "oval-oval" scheme. This pressure treatment process is similar to the stress state diagram of a real rolling process in a cold-rolling mill.

After reaching the required degree of deformation, 2 samples were taken from the bar for static tension. Static tensile tests at room temperature in accordance with GOST (Russian state standard) 1497-84 «Metals. Methods of tension test» [11] were carried out on a tensile testing machine SSI MTSInsight 100.

\section{EXPERIMENTAL PART}

Cold deformation was carried out in the mode of sequential increase in the compression value. Photographs of Appearance of samples after testing are shown in Figure 2 Photographs of specimens rolled with varying degrees of deformation are shown in Figure 3.

The degree of deformation $\varepsilon$ was calculated using the following formula:

$$
\varepsilon=\frac{F_{0}-F_{1}}{F_{0}} \cdot 100 \%
$$

where, $\varepsilon$ is degree of deformation, $F_{0}$ is the area of an undeformed bar, $F_{1}$ is the area of the deformed bar.

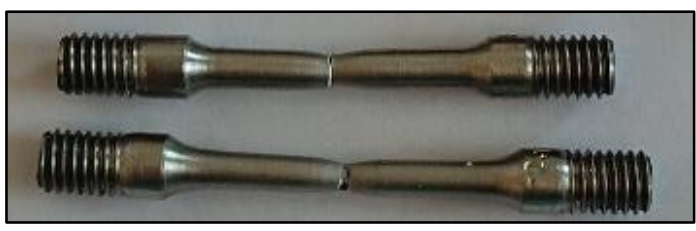

Figure 2. Tensile samples after testing 


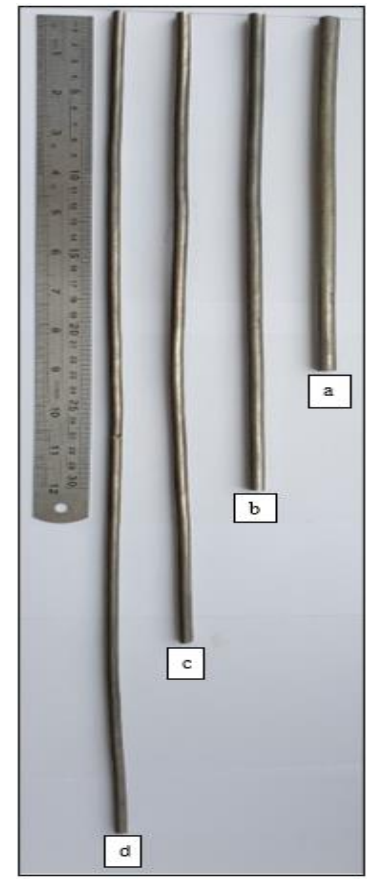

Figure 3. Rolled samples with varying degrees of deformation $\varepsilon: a-\varepsilon=9.75 \% ; b-\varepsilon=31.11 \% ; c-\varepsilon=48.16 \%$; $\mathrm{d}-\varepsilon=61.56 \%$

\section{RESULT PROCESSING}

Tables 1 and 2 show the tensile test results. Figures 4 and 5 show the empirical curves of the change in temporary resistance, yield point, and relative elongation versus the degree of deformation.

Table 1. Results of mechanical tests of samples

\begin{tabular}{cccccc}
\hline & $\varnothing$ & $\sigma_{\mathrm{B}}$ & $\sigma_{0,2}$ & $\delta$ & $\varepsilon$ \\
№ & $\mathrm{Mm}$ & $\mathrm{N} / \mathrm{mm}^{2}$ & $\mathrm{~N} / \mathrm{mm}^{2}$ & $\%$ & $\%$ \\
\hline $1-1$ & 6.09 & 833 & 481 & 45.0 & 0 \\
$1-2$ & 6.12 & 846 & 481 & 47.3 & \\
$2-1$ & 5.16 & 943 & 764 & 30.4 & 9.75 \\
$2-2$ & 5.15 & 918 & 729 & 29.2 & 31.11 \\
$3-1$ & 5.12 & 1267 & 1153 & 8.1 & \\
$3-2$ & 5.18 & 1250 & 1150 & 8.8 & \\
$4-1$ & 4.09 & 1400 & 1153 & 7.3 & 48.16 \\
$4-2$ & 4.09 & 1393 & 1282 & 45.0 & \\
$5-1$ & 4.11 & 1522 & 1408 & 47.3 & \multirow{2}{*}{61.56} \\
5-2 & 4.09 & 1517 & 1395 & 30.4 & \\
\hline
\end{tabular}

where, $\varnothing$ is diameter of the sample, $\sigma_{b}$ is temporary resistance, $\sigma_{0,2}$ is yeld point, $\delta$ is relative extension, $\varepsilon$ degree of deformation.

Table 2. Mechanical properties of the researched samples, depending on the degree of deformation

\begin{tabular}{cccc}
\hline $\begin{array}{c}\text { degree of } \\
\text { deformation, } \\
\%\end{array}$ & $\begin{array}{c}\text { temporary } \\
\text { resistance } \sigma_{\mathrm{B}}, \\
\mathrm{N} / \mathrm{mm}^{2}\end{array}$ & $\begin{array}{c}\text { yield } \\
\text { point } \sigma_{0,2}, \\
\mathrm{~N} / \mathrm{mm}^{2}\end{array}$ & $\begin{array}{c}\text { relative } \\
\text { extension } \\
\delta, \%\end{array}$ \\
\hline 0 & 839 & 481 & 46.2 \\
9.75 & 931 & 746 & 29.8 \\
31.11 & 1258 & 1152 & 8.4 \\
48.16 & 1396 & 1218 & 7.1 \\
61.56 & 1520 & 1401 & 6.5 \\
\hline
\end{tabular}

Thus, the change in the mechanical properties of the CrNi60WT alloy depending on the degree of cold deformation can be represented by the following functions: for temporary resistance:

$$
\sigma_{\mathrm{B}}(\varepsilon)=846,1+11,379 \varepsilon
$$

for yield point:

$$
\sigma_{0,2}(\varepsilon)=14,219 \varepsilon+571,37
$$

for relative extension:

$$
\delta(\varepsilon)=0,0176 \varepsilon^{2}-1,695 \varepsilon+45,44
$$

where, $\epsilon$ is the degree of deformation, $\%$.

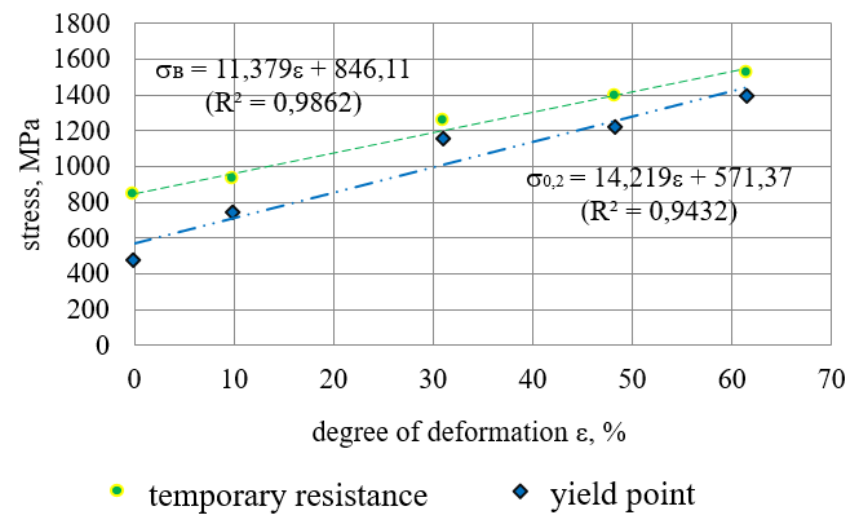

Figure 4. Dependence of temporary resistance and yield point on the degree of cold deformation

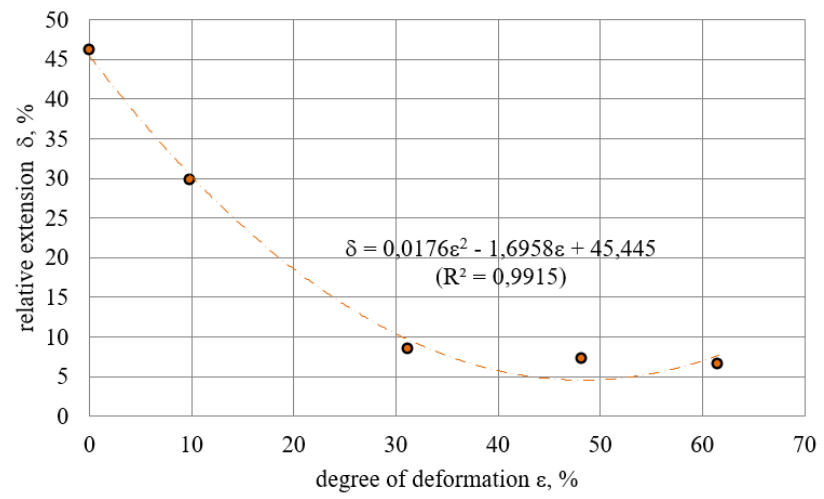

Figure 5. Dependence of the relative elongation on the degree of deformation

\section{CONCLUSION}

Alloy CrNi60WT has high ductility with high strength properties. Analysis of the surface of the rods after cold deformation showed that even with a degree of deformation of more than $60 \%$, failure is not observed.

An experimental study of the effect of cold plastic deformation on the mechanical properties of the CrNi60WT alloy was carried out. Empirical dependences of the yield point, ultimate strength, and relative elongation on the degree of deformation were calculated. 


\section{REFERENCES}

[1] Presentation material of the NGO "Pipe Industry Development Fund" on the results of the work of the Russian pipe industry in 2017, achievements, trends and challenges of the industry. Forecasts for 2018. [Electronic resource] / I.A. Malyshev. - Electron. text data. - Moscow: [b.i.], 2017. - Access mode: http://www.frtp.ru/node/1026.

[2] Etelmin, V.V. (2009). Oil and gas business. Complete course. Tutorial. / V.V. Tetelmin, V.A. Yazev. Dolgoprudny: Publishing House "Intellect".

[3] Bauser, M., Siegert, K. (2006). Extrusion. ASM international. 2nd ed.; translated from German by A.F. Castle. - Ohio: ASM International.

[4] Tarasov, D., Milder, O., Tyagunov, A. (2018). Application of artificial neural networks for the replenishment of nickel-based superalloys catalogues. In 2018 2nd European Conference on Electrical Engineering and Computer Science (EECS), pp. 41-44. https://doi.org/10.1109/EECS.2018.00017

[5] Feng, K., Kapadia, N., Castaldi, S., Ganjei, J., Ryoo, S., Kim, K., Lee, J., Bang, Y. (2010). Ni/Cr alloy stripper for flexible wiring boards. In 2010 5th International Microsystems Packaging Assembly and Circuits Technology Conference, Taipei, Taiwan, pp. 1-4. https://doi.org/10.1109/IMPACT.2010.5699509

[6] Bumgardner, J.D., Roach, M., Scheelz, T., Gardner, S. (1998). Corrosion and XPS surface evaluation of nickelchromium based dental casting alloys. In Proceedings of the 17th Southern Biomedical Engineering Conference,
San Antonio, TX, USA, pp. 45-45. https://doi.org/10.1109/SBEC.1998.666651

[7] Shi, Y.Y., Zhao, C., Qi, M., Liu, Y.B., Deng, P.F. (2013) Research on the cutting force of nickel-based superalloy. 2013 Fourth International Conference on Intelligent Systems Design and Engineering Applications, Zhangjiajie, https://doi.org/10.1109/ISDEA.2013.525

[8] Tarasov, D., Milder, O., Tyagunov, A. (2019). Application of bayesian artificial neural networks for modeling the dependence of nickel-based superalloys' ultimate tensile strength on their chemical composition. In 2019 International Conference on Control, Artificial Intelligence, Robotics \& Optimization (ICCAIRO), Athens, Greece, pp. 54-60. https://doi.org/10.1109/ICCAIRO47923.2019.00018

[9] Jiang, Y., Liu, Y., Li, M., Deng, S. (2018). Experimental research on micro electrochemical milling of nickelbased superalloy by using high-speed rotary helical electrode with high frequency pulse power supply. In 2018 IEEE International Conference on Information and Automation (ICIA), Wuyishan, China, pp. 710-715. https://doi.org/10.1109/ICInfA.2018.8812369

[10] Haq, A.U., Xiaoguang, Y., Duoqi, S. (2018). Isothermal tensile, cyclic behaviour and constitutive modelling of nickel-based directionally solidified superalloy. In 2018 15th International Bhurban Conference on Applied Sciences and Technology (IBCAST), pp. 150-157. https://doi.org/10.1109/IBCAST.2018.8312215

[11] GOST (Russian state standard) 1497-84 «Metals. Methods of tension test». 